\title{
Articles
}

\section{Photoemission Study on the Adsorption of Ethanol on Chemically Modified $\mathrm{TiO}_{2}(001)$ Surfaces}

\author{
Ja Hyun Kong and Yu Kwon Kim* \\ Department of Energy Systems Research and Department of Chemistry, Ajou University, Suwon 443-749, Korea \\ *E-mail:yukwonkim@ajou.ac.kr \\ Received June 7, 2011, Accepted June 11, 2011
}

\begin{abstract}
Ethanol is a prototype molecule used in probing catalytic reactivity of oxide catalysts such as $\mathrm{TiO}_{2}$. In the present study, we adsorbed ethanol on $\mathrm{TiO}_{2}(001)$ at room temperature (RT) and the corresponding bonding state of ethanol was systematically studied by x-ray photoemission spectroscopy (XPS) using synchrotron radiation. Especially, we compared $\mathrm{TiO}_{2}(001)$ surfaces prepared in ultra-high vacuum (UHV) with different surface treatments such as $\mathrm{Ar}^{+}$-sputtering and oxidation with molecular $\mathrm{O}_{2}$, respectively. We find that the saturation coverage of ethanol at RT varies depending on the amount of reduced surface defects (e.g., $\mathrm{Ti}^{3+}$ ) which are introduced by $\mathrm{Ar}^{+}$-sputtering. We also find that the oxidized $\mathrm{TiO}_{2}(001)$ surface has other type of surface defects (not related to Ti $3 d$ state) which can dissociate ethanol for further reaction above $600 \mathrm{~K}$. Our $\mathrm{C} 1 s$ core level spectra indicate clearly resolved features for the two chemically distinct carbon atoms from ethanol adsorbed on $\mathrm{TiO}_{2}(001)$, showing the adsorption of ethanol proceeds without $\mathrm{C}-\mathrm{C}$ bond dissociation. No other $\mathrm{C} 1 s$ feature for a possible oxidized intermediate was observed up to the substrate temperature of $650 \mathrm{~K}$.
\end{abstract}

Key Words : Photoemission spectroscopy, Adsorption, Ethanol, $\mathrm{TiO}_{2}(001)$

\section{Introduction}

$\mathrm{TiO}_{2}$ has been known as a potential photocatalyst not only for the oxidation of organic molecules ${ }^{1,2}$ but also for the water-splitting reaction for the production of $\mathrm{H}_{2}{ }^{3}$ For this reason, intense research effort has been made to understand the origin of the $\mathrm{TiO}_{2}$-catalyzed reactions of simple molecules such as $\mathrm{H}_{2} \mathrm{O},{ }^{4-6} \mathrm{O}_{2},{ }^{7-10}$ alcohols, ${ }^{11-13}$ and aldehydes. ${ }^{14,15}$

It has been found that defects on $\mathrm{TiO}_{2}$ play a dominant role in the initial dissociation of such reactant molecules. In addition to $\mathrm{Ti}^{3+}$ interstitials in the bulk, $\mathrm{TiO}_{2}$ has various kinds of surface defects such as oxygen vacancies ${ }^{16,17}$ and oxygen adatoms, ${ }^{9,10,18}$ which are reported to be reaction sites for $\mathrm{H}_{2} \mathrm{O},{ }^{5,9,10} \mathrm{O}_{2},{ }^{8,18}$ and alcohols. ${ }^{11}$ Also, recent reports indicate that $\mathrm{Ti}^{3+}$ interstitials ${ }^{19}$ in the subsurface region are important in a catalytic coupling reaction of aldehydes. ${ }^{14,15}$

Photoemission studies can provide an important information on the electronic nature of such intrinsic defects which appear as a distinct band-gap state located at $0.9 \mathrm{eV}$ below Fermi level $\left(E_{F}\right){ }^{20,21}$ The Ti $3 d$ character of the bandgap state is observed ${ }^{21}$ and is generally related to the excess charge associated with defects near the surface region such as oxygen vacancies ${ }^{17,21}$ and $\mathrm{Ti}^{3+}$ interstitials. ${ }^{17,19}$

Surface defects can be intentionally induced by various surface treatments in UHV. An atomically well-ordered $\mathrm{TiO}_{2}$ surface can be prepared by a few cycles of sputtering and annealing to $900 \mathrm{~K}$ without any significant reduction. $\mathrm{Ar}^{+}-$ sputtering may be used to prepare a $\mathrm{Ti}^{3+}$-rich $\mathrm{TiO}_{2}$ surface due to a preferential removal of surface oxygen atoms under a mild sputtering condition. Also, the reduced $\mathrm{Ti}^{3+}$ subsurface defects can be removed by the interaction with molecular $\mathrm{O}_{2}$ at RT. ${ }^{19}$ A prolonged dose of $\mathrm{O}_{2}$ (up to $1000 \mathrm{~L}$ ) is reported to induce the band-gap state completely suppressed, which is attributed to oxidation of $\mathrm{Ti}^{3+}$ interstitials nearby the surface region. ${ }^{19}$ Also, the dissociative adsorption of molecular oxygen over oxygen vacancies is known to produce another type of surface defect which is an oxygen adatom. ${ }^{18}$

The oxygen vacancy is reported to be a reaction site for the dissociative adsorption of ethanol. ${ }^{11,22-24}$ On the oxygen vacancy, the adsorption of ethanol proceeds by breaking $\mathrm{O}-\mathrm{H}$ bond to produce ethoxy $\left(\mathrm{CH}_{3} \mathrm{CH}_{2} \mathrm{O}-\right)$ bound to the oxygen vacancy and hydrogen bound to a neighboring bridgebonded oxygen atom. ${ }^{11,22-24}$ A further catalytic decomposition of such alkoxy species can occur above $600 \mathrm{~K}$ through various competing reaction channels such as dehydration (alkene), dehydrogenation (aldehydes) and recombinative desorption (alcohol) as has been studied for simple aliphatic alcohols such as ethanol ${ }^{24,25}$ and propanol. ${ }^{12,26}$

In the present study, we aim to enhance our understanding on the interaction of ethanol with such defects on a welldefined model oxide catalyst such as rutile $\mathrm{TiO}_{2}(001)$ using photoemission spectroscopy. While the oxygen vacancy is generally accepted to be a reaction site for the dissociative adsorption of ethanol, the role of other types of defects are not well-understood. To gain further insight into the role of 
such defects on the catalytic reactivity of $\mathrm{TiO}_{2}$, we compare the adsorption property of ethanol on $\mathrm{TiO}_{2}(001)$ surfaces with various kinds of surface defects. The new insight gained from the present study is that the saturation coverage of ethanol at RT depends on the amount of reduced $\mathrm{Ti}^{3+}$ surface defects. While no oxidized intermediate is found from the RT adsorption of ethanol on our $\mathrm{TiO}_{2}(001)$ surfaces, the saturation coverage of ethanol at RT is found to be enhanced on the surface with high $\mathrm{Ti}^{3+}$ defect concentration. The oxidized $\mathrm{TiO}_{2}(001)$ surface is depleted with the $\mathrm{Ti}^{3+}$ defects, but may have oxygen adatoms which are attributed to the reason for the increase of the maximum desorption temperature of ethanol. Our C $1 s$ core level photoemission spectra also confirm that ethanol preserves its $\mathrm{C}-\mathrm{C}$ bond on our $\mathrm{TiO}_{2}(001)$ surfaces until it desorbs at around $600 \mathrm{~K}$.

\section{Experimental Details}

A single crystal $\mathrm{TiO}_{2}(001)$ substrate $(0.5 \mathrm{~mm}$ thick, oneside polished, MTI) was cut into $5 \mathrm{~mm} \times 10 \mathrm{~mm}$ in size and ceramic-glued on a thin Ta foil and was introduced into a UHV chamber attached 7B1 beamline ${ }^{27}$ at Pohang Accelerator Laboratory (PAL). For a temperature measurement, Ktype thermocouple was spot-welded on the edge of the Ta foil wrapped around the $\mathrm{TiO}_{2}$ crystal. A well-ordered and clean $\mathrm{TiO}_{2}(001)$ is prepared by a few cycles of $\mathrm{Ar}^{+}$-sputtering at $1 \mathrm{keV}$ and annealing at $900 \mathrm{~K}$. A clean $\mathrm{TiO}_{2}(001)$ surface showed very sharp integer spots in LEED pattern indicating a large atomically ordered domain structure has been obtained.

A fair amount of experimental and theoretical studies were reported to elucidate the atomic structure of the $\mathrm{TiO}_{2}(001)$ surface. $^{28-31}$ While the detailed atomic structure may vary depending on the treatment condition, theoretical studies show that the ideal (001) surface has two kinds of surface species which are a four-fold $\mathrm{Ti}^{4+}$ and a twofold oxygen. ${ }^{30}$ Due to the high surface free energy of the (001) facet compared to other facets, the $\mathrm{TiO}_{2}(001)$ surface was reported to undergo a surface reconstruction where the oxygen moves outwards and the titanium moves inwards. ${ }^{31}$ Annealing above $1000 \mathrm{~K}$ may induce low surface energy facets in which 5fold $\mathrm{Ti}^{4+}$ may coexist with 4 -fold $\mathrm{Ti}^{4+} .{ }^{29}$ Considering our experimental conditions, our clean $\mathrm{TiO}_{2}(001)$ surface is expected to be composed of a reconstructed surface with a four-fold $\mathrm{Ti}^{4+}$ and a twofold oxygen.

For a systematic preparation of surface defects, oxidation of $\mathrm{TiO}_{2}(001)$ surface was performed by backfilling the chamber with $\mathrm{O}_{2}(99.999 \%)$ using a variable leak valve up to an $\mathrm{O}_{2}$ ambient pressure of $10^{-6}$ torr. A defective $\mathrm{TiO}_{2}(001)$ surface was prepared by an $\mathrm{Ar}^{+}$-sputtering $\left(\mathrm{P}_{\mathrm{Ar}}=1 \times 10^{6}\right.$ torr, $\mathrm{E}_{\mathrm{Ar}}{ }^{+}=1 \mathrm{keV}, \mathrm{I}=1 \mu \mathrm{A}, \mathrm{t}=5 \mathrm{~min}$ ) at RT.

Ethanol was further purified by repeated freeze-pump-saw cycles prior to use and was dosed onto the $\mathrm{TiO}_{2}$ substrate by backfilling the UHV chamber using a variable leak valve while the substrate was kept at RT.

XPS measurements were performed at the 7B1 beamline.
Photoemission spectra of Ti $2 p$, O $1 s$, and $\mathrm{C} 1 s$ core levels were taken using a commercial electron analyzer (PHOIBOS 150 , SPECS) at a fixed normal emission at RT. Photon energies used for the measurement of $\mathrm{Ti} 2 p, \mathrm{C} 1 s$ and valence band were $580 \mathrm{eV}, 335 \mathrm{eV}$ and $55 \mathrm{eV}$, respectively. The binding energies of the photoemission spectra were determined by the position of the Fermi edge of Ta foil in contact with the $\mathrm{TiO}_{2}$ substrate. The $\mathrm{C} 1 s$ core level spectra are carefully analyzed using a standard nonlinear leastsquares fitting procedure with Voigt functions. ${ }^{32}$

\section{Results and Discussion}

We compare Ti $2 p$ core level and valence band spectra of our three $\mathrm{TiO}_{2}(001)$ surfaces, which are an atomically ordered $\mathrm{TiO}_{2}(001)$, an oxidized $\mathrm{TiO}_{2}(001)$, and $\mathrm{Ar}^{+}$-sputtered $\mathrm{TiO}_{2}(001)$ surfaces in Figure 1 and Figure 2, respectively. As shown in Figure 1 , the $\mathrm{Ti} 2 p$ core level from $\mathrm{TiO}_{2}$ is characterized by the main Ti $2 p_{3 / 2}$ peak at $459 \mathrm{eV}$, which is assigned to $\mathrm{Ti}^{4+}$ species in the $\mathrm{TiO}_{2}$ lattice. ${ }^{33-35}$ Both the clean and the oxidized $\mathrm{TiO}_{2}(001)$ surfaces show a welldistinguished single peak at $459 \mathrm{eV}$, suggesting $\mathrm{Ti}^{4+}$ from a stoichiometric $\mathrm{TiO}_{2}$ lattice is a dominant feature for both surfaces. A detailed comparison between the two surfaces show a minor shoulder feature (indicated by arrow) on the lower binding energy side of the main Ti $2 p_{3 / 2}$ peak on the clean $\mathrm{TiO}_{2}(110)$ surface. This minor low-binding energy feature may be attributed to a reduced $\mathrm{Ti}^{3+}$ species near the surface region. It has been reported that the RT oxidation of $\mathrm{TiO}_{2}(110)$ decreases the population of $\mathrm{Ti}^{3+}$ interstitials in the subsurface region. ${ }^{19}$ On the $\mathrm{Ar}^{+}$-sputtered $\mathrm{TiO}_{2}(001)$, the Ti $2 p_{3 / 2}$ peak becomes even more pronounced toward lower

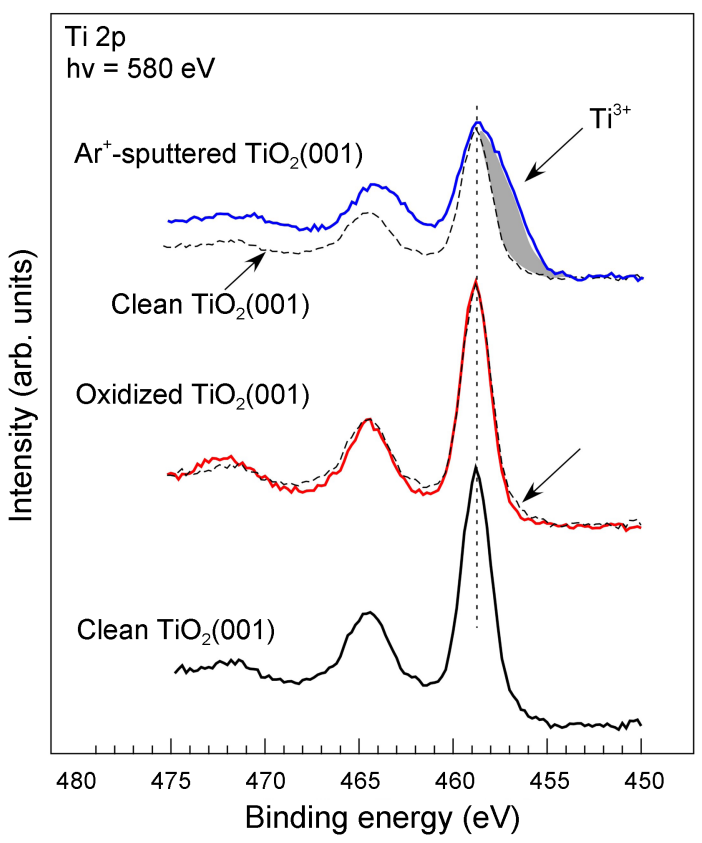

Figure 1. Ti $2 p$ core level spectra taken from clean, oxidized, and $\mathrm{Ar}^{+}$-sputtered $\mathrm{TiO}_{2}(001)$ surfaces. Enhanced population of reduced $\mathrm{Ti}^{3+}$ state on the lower binding energy side of $\mathrm{Ti} 2 p_{3 / 2}$ peak is indicated by arrows. 


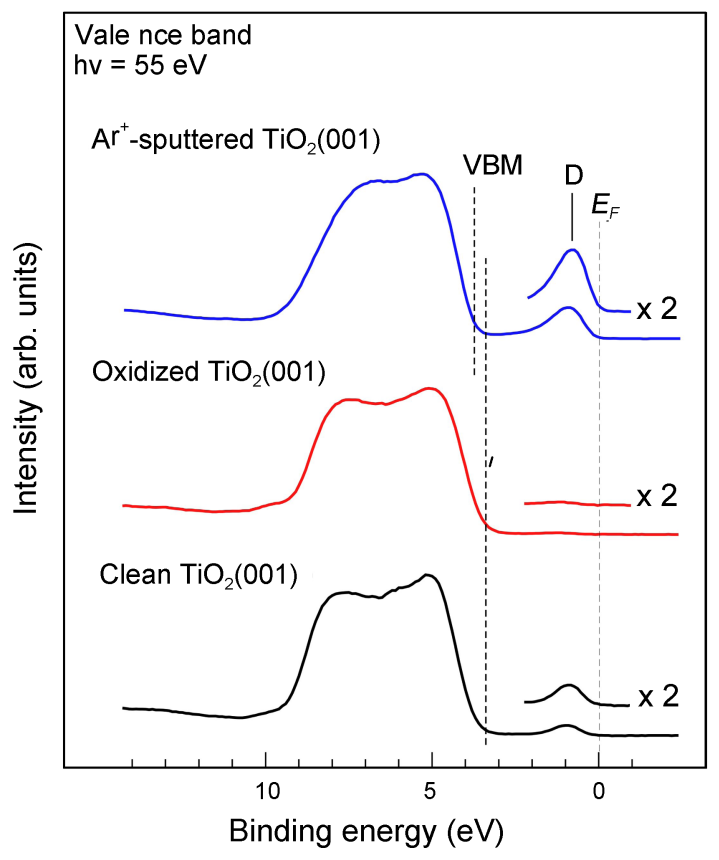

Figure 2. Valence band spectra taken from clean, oxidized, and $\mathrm{Ar}^{+}$-sputtered $\mathrm{TiO}_{2}(001)$ surfaces. The band-gap state (D) varies on the three surfaces and reflects the population of $\mathrm{Ti} 3 d$ state associated with surface defects such as oxygen vacancies and $\mathrm{Ti}^{3+}$ interstitials.

binding energy due to an enhanced population of $\mathrm{Ti}^{3+}$ species on the surface.

The variation of $\mathrm{Ti}^{3+}$-related surface defects on the three surfaces is further examined in the valence band spectra in Figure 2. The broad feature at $3-9 \mathrm{eV}$ is associated with $\mathrm{O} 2 p$ state of $\mathrm{TiO}_{2}{ }^{20,36} \mathrm{In}$ addition, the distinct feature (D) at 0.9 $\mathrm{eV}$ below $E_{F}$ is named the band-gap state and is associated with $\mathrm{Ti} 3 d$ state. ${ }^{20}$ The clean $\mathrm{TiO}_{2}(001)$ surface prepared in UHV shows a well-distinguished peak at $0.9 \mathrm{eV}$, while the state becomes completely suppressed on the oxidized $\mathrm{TiO}_{2}(001)$ surface. On the $\mathrm{Ar}^{+}$-sputtered $\mathrm{TiO}_{2}(001)$ surface, the gap state is enhanced by three times compared to that on the clean surface. The magnitude of the band-gap state is related to the population of $\mathrm{Ti}^{3+}$ species (probably in the form of interstitials) on or near the surface region. In addition, a depletion of surface oxygen is noted from an attenuation in the $\mathrm{O} 2 p$ state at $3 \mathrm{eV}$ leading to an increase of the band gap. Thus, the results in Figure 1 and Figure 2 agree with each other and compare the relative population of $\mathrm{Ti}^{3+}$ species on the three $\mathrm{TiO}_{2}(001)$ surfaces.

Figure 3 shows $\mathrm{C} 1 s$ core level spectra of ethanol adsorbed on the clean $\mathrm{TiO}_{2}(001)$ surface. The $\mathrm{C} 1 s$ spectra taken after successively increasing ethanol dose of $5,10,20 \mathrm{~L}$ at RT (not shown here) indicate that the peak intensity does not increase above $5 \mathrm{~L}$, suggesting that the RT saturation coverage is already achieved at the ethanol dose of $5 \mathrm{~L}$. The two resolved peaks are attributed to the two chemically different carbon atoms of ethanol. Detailed fitting analysis (in Fig. 3) reproduces the two $\mathrm{C} 1 s$ components positioned at 285.3 and $286.6 \mathrm{eV}$, respectively. The difference in the binding energies

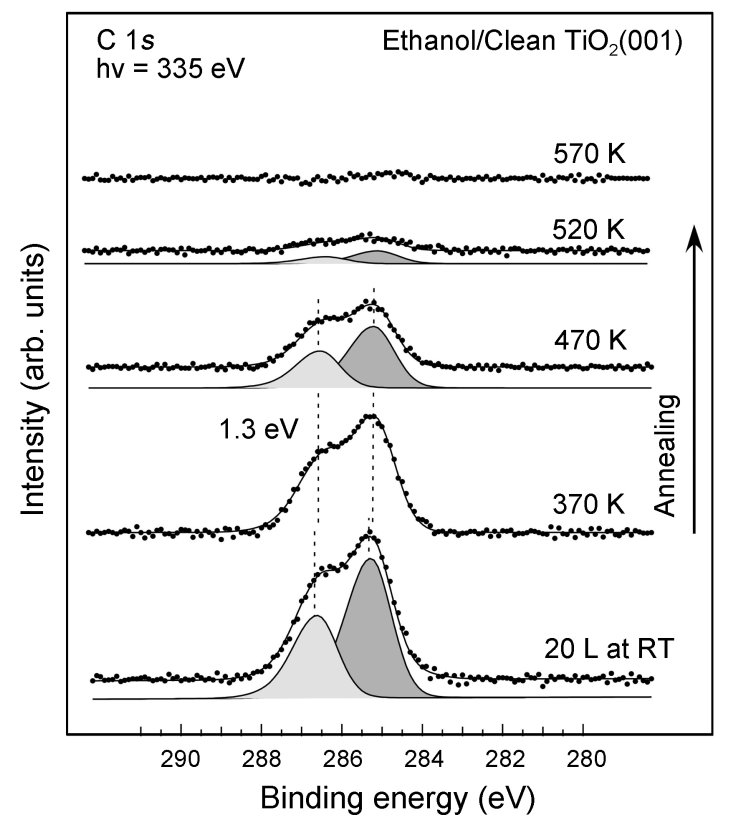

Figure 3. The $\mathrm{C} 1 s$ core level spectra taken from ethanol adsorbed on the clean $\mathrm{TiO}_{2}(001)$ surface at RT up to a saturation coverage and after subsequent annealing to higher temperatures.

between the two components is measured to be about $1.3 \mathrm{eV}$. The peak shape is found to be asymmetric and has a tail toward higher binding energies due to the contribution of C-H vibrational satellite. ${ }^{37}$ The peak at $285.3 \mathrm{eV}$ is assigned to the $\beta$-carbon atom $\left(-\mathrm{CH}_{3}\right)$ and the peak at $286.6 \mathrm{eV}$ to the $\alpha$-carbon atom (-O- $\left.-\mathrm{CH}_{2}-\right)^{26,38}$ The intensity ratio between the two peaks is measured to be 1.6-1.7 (which is far from 1 ), while we assume a one-to-one ratio in the populations of the two carbon atoms. We speculate the origin is related to

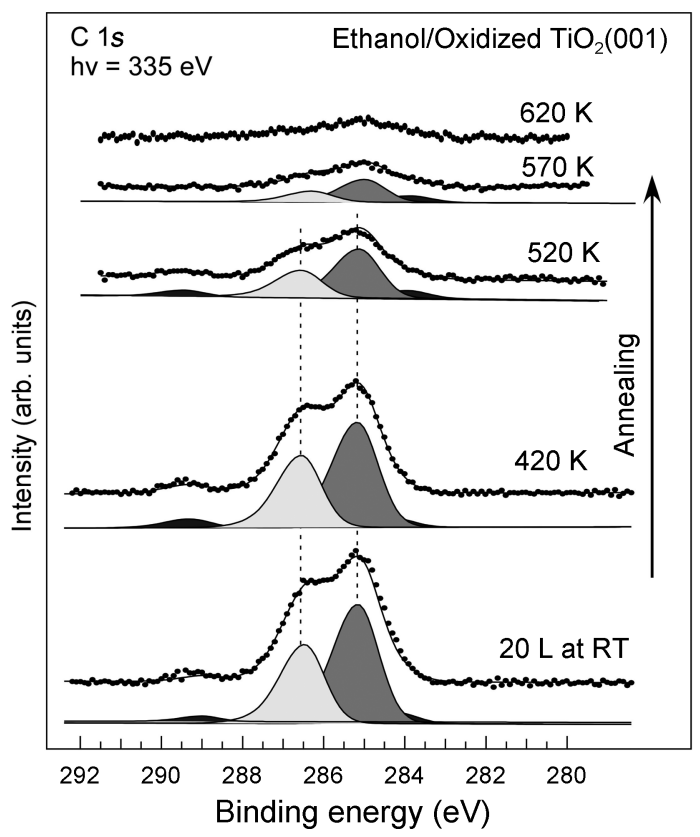

Figure 4. The $\mathrm{C} 1 s$ core level spectra taken from ethanol adsorbed on the oxidized $\mathrm{TiO}_{2}(001)$ surface at RT up to a saturation coverage and after subsequent annealing to higher temperatures. 
the bonding geometry of ethanol where ethanol is bonded to $\mathrm{Ti}^{4+}$ by its oxygen atom, thus makes the $\beta$-carbon $\left(\mathrm{CH}_{3^{-}}\right)$ more surface-sensitive.

After successive annealing to higher temperatures, both $\mathrm{C}$ $1 s$ peaks decrease gradually until they are completely removed by $570 \mathrm{~K}$. The result agrees with earlier reports that ethanol adsorbs on $\mathrm{TiO}_{2}$ either molecularly on $\mathrm{Ti}^{4+}$ sites $^{22,26}$ or dissociatively ${ }^{22,24,26}$ on defect sites as an ethoxy $\left(\mathrm{CH}_{3} \mathrm{CH}_{2} \mathrm{O}-\right)$ and a hydrogen $(-\mathrm{H})$. The catalytic decomposition of the ethoxy may occur at higher desorption temperatures $(>600 \mathrm{~K})$ followed by desorption of reaction products. No other feature indicative of any oxidized intermediate is found.

Figure 4 shows the $\mathrm{C} 1 \mathrm{~s}$ core level spectra for ethanol on the oxidized $\mathrm{TiO}_{2}(001)$ surface at RT as well as after subsequent annealing to higher temperatures. We find the two main C $1 s$ components at 285.2 and $286.5 \mathrm{eV}$, respectively, which shows again the difference in the chemical shifts between the two components to be about $1.3 \mathrm{eV}$. In addition, we notice additional features at $289 \mathrm{eV}$ and $284.3 \mathrm{eV}$, respectively. In fact, both features are not related to ethanol. Instead, they are attributed to a possible contamination introduced on the $\mathrm{TiO}_{2}$ surface during prolonged $\mathrm{O}_{2}$ dose up to $1000 \mathrm{~L}$ in our chamber since we observe the same features even after the RT oxidation of the $\mathrm{TiO}_{2}(001)$ surface. Thus, we disregard those features in our discussion.

After successive annealing to higher temperatures, we observe that both $\mathrm{C} 1 s$ features gradually decrease with increasing annealing temperatures. We also note that the ethanol-related C $1 s$ features at $285-286.5 \mathrm{eV}$ persist even above $600 \mathrm{~K}$.

The increase of the maximum desorption temperature on the oxidized $\mathrm{TiO}_{2}(001)$ surface is related to a stronger binding site which may involve surface defects such as an oxygen adatom, where a dissociative adsorption of ethanol may occur. On $\mathrm{TiO}_{2}(110)$, dissociative adsorption of ethanol is reported to leave ethoxy bound to oxygen vacancy on the surface. ${ }^{23,24,39}$ After the hydroxyl hydrogen atoms (dissociated from ethanol) desorb from the surface as $\mathrm{H}_{2} \mathrm{O}$ by $500 \mathrm{~K}$, a recombinative ethanol desorption of ethoxy (left on the surface) is suppressed because no hydrogen is left on the surface by that temperature. Instead, catalytic decompositions of such ethoxy species are reported to occur on $\mathrm{TiO}_{2}(110)$ above $600 \mathrm{~K} \cdot{ }^{22,24,26} \mathrm{We}$ assume that oxygen vacancy is depleted on the oxidized surface due to dissociative adsorption of molecular oxygen, which would necessarily leave an oxygen adatom on the surface. We speculate that the $\mathrm{C} 1 s$ species left after the annealing temperatures above $570 \mathrm{~K}$ is related to a dissociatively adsorbed ethoxy on a surface defect such as a low-coordinated oxygen adatom.

Figure 5 shows the $\mathrm{C} 1 \mathrm{~s}$ core level spectra for ethanol on our $\mathrm{Ar}^{+}$-sputtered $\mathrm{TiO}_{2}(001)$ surface at RT as well as after subsequent annealing to higher temperatures. We find again the two main $\mathrm{C} 1 s$ components at 285.2 and $286.6 \mathrm{eV}$, respectively. Here, the difference in the chemical shifts between the two $\mathrm{C} 1 s$ components is measured to be $1.4 \mathrm{eV}$. We defy any further discussion on the chemical shift differ-

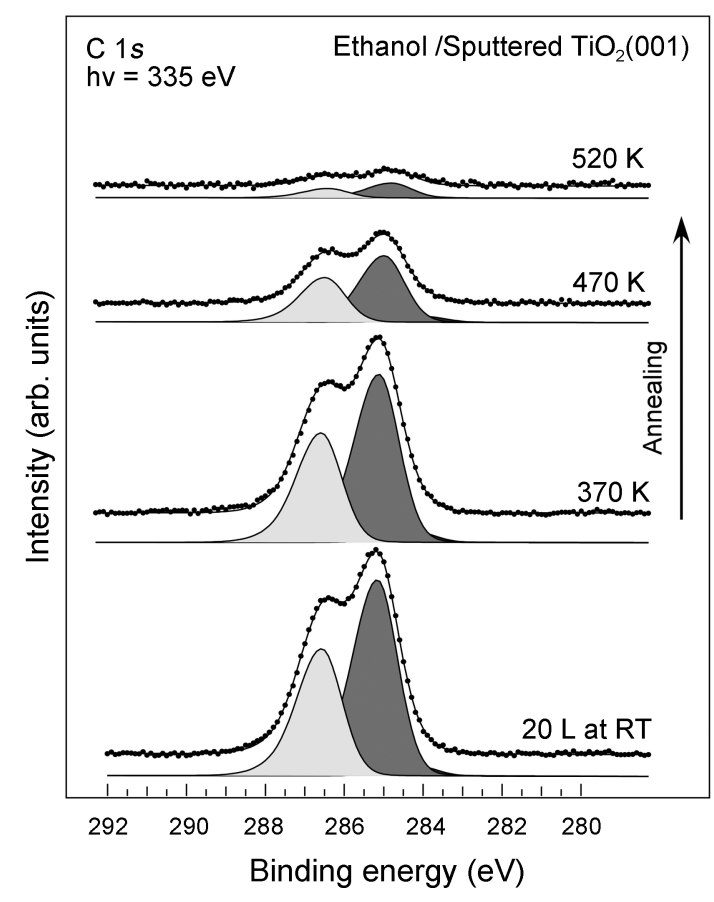

Figure 5. The $\mathrm{C} 1 s$ core level spectra taken from ethanol adsorbed on the $\mathrm{Ar}^{+}$-sputtered $\mathrm{TiO}_{2}(001)$ surface at RT up to a saturation coverage and after subsequent annealing to higher temperatures.

ence between 1.3 and $1.4 \mathrm{eV}$ considering the uncertainty in our peak position measurements $( \pm 0.1 \mathrm{eV})$. After successive annealing to higher temperatures, we find again a gradual decrease of both $\mathrm{C} 1 \mathrm{~s}$ peaks until they completely disappear by $570 \mathrm{~K}$ probably due to the desorption of ethanol.

The integrated area of the two C $1 s$ features at 285-286.5 $\mathrm{eV}$ may be used to estimate the amount of ethanol adsorbed on the $\mathrm{TiO}_{2}$ surfaces. In Figure 6, we show our estimated number of ethanol molecules calculated by considering the sensitivity of C $1 s$ core level compared to $\mathrm{O} 1 s$ core level.

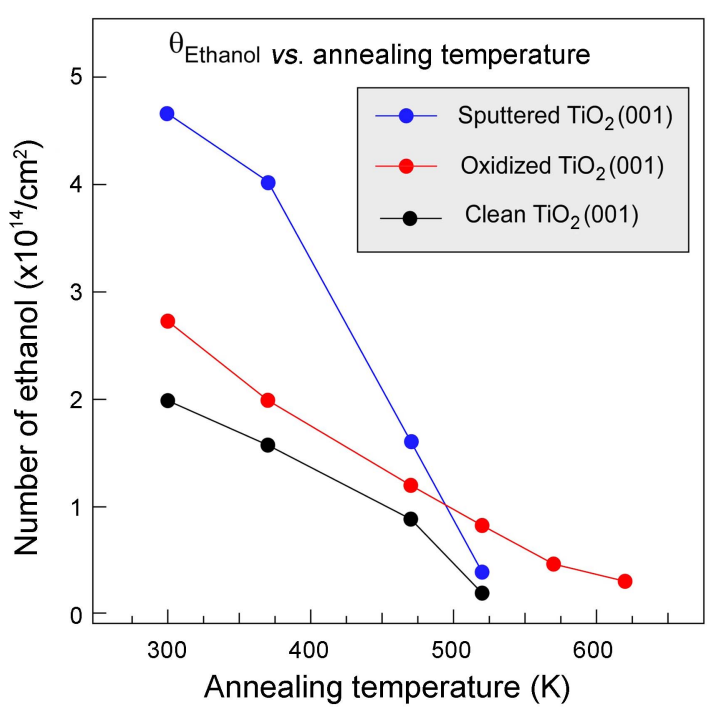

Figure 6. A variation in the amount of ethanol adsorbed on each $\mathrm{TiO}_{2}(001)$ surface at RT as the substrate temperature is raised to higher temperatures. 
Due to a possible huge uncertainty associated with our estimation, we focus on the relative coverage of ethanol on the various $\mathrm{TiO}_{2}(001)$ surfaces. We note here that the initial saturation coverage of ethanol on sputtered $\mathrm{TiO}_{2}(001)$ is greatly enhanced compared to that on the clean and the oxidized $\mathrm{TiO}_{2}(001)$ surfaces.

Figure 6 also shows how the coverage of ethanol varies on the various $\mathrm{TiO}_{2}(001)$ surfaces at RT as well as after annealing to higher temperatures. Here, we find two noticeable trends: (1) On the clean and $\mathrm{Ar}^{+}$-sputtered $\mathrm{TiO}_{2}(001)$ surfaces, the surface coverage of ethanol approaches to zero by $550 \mathrm{~K}$, while that is extended to higher temperatures above $600 \mathrm{~K}$ on the oxidized $\mathrm{TiO}_{2}(001)$. (2) The initial saturation coverage of ethanol on the $\mathrm{Ar}^{+}$-sputtered $\mathrm{TiO}_{2}(001)$ is higher than that on the clean surface.

The observation (1) gives an additional insight into the characteristics of the surface defect state of $\mathrm{TiO}_{2}(001)$. The fact that the desorption of ethanol completes by $550 \mathrm{~K}$ may suggest that there is no such defective site as oxygen vacancies on the clean $\mathrm{TiO}_{2}(001)$ surface since it is known that the dissociative adsorption of ethanol on the oxygen vacancy of $\mathrm{TiO}_{2}(110)$ is removed only above $600 \mathrm{~K}$. While no oxygen vacancy is expected on the clean $\mathrm{TiO}_{2}(001)$, the valence band in Figure 2 shows the band-gap state suggesting the presence of Ti $3 d$ state. Thus, the band-gap state is related to $\mathrm{Ti}^{3+}$ interstitials instead of oxygen vacancies on $\mathrm{TiO}_{2}(001)$.

The observation (2) suggests that the saturation coverage of ethanol at RT may be related to $\mathrm{Ti}^{3+}$ defects on the surface. The Ti $2 p$ core level of the clean $\mathrm{TiO}_{2}(001)$ surface in Figure 1 shows that the dominant Ti species is in the form of $\mathrm{Ti}^{4+}$ instead of $\mathrm{Ti}^{3+}$ defects. In general, it is believed that the surface concentration of $\mathrm{Ti}^{3+}$ defects should be in equilibrium with that in the bulk (or subsurface) after the final annealing to $900 \mathrm{~K}$. Thus, a major fraction of $\mathrm{Ti}^{3+}$ should be present in the subsurface and may have an influence on the binding of ethanol at RT. On the $\mathrm{Ar}^{+}$-sputtered $\mathrm{TiO}_{2}(001)$, the excess $\mathrm{Ti}^{3+}$ defects on the surface are considered to be the origin of the increased saturation coverage of ethanol.

It is also interesting to note that the saturation coverage of ethanol on the oxidized surface is still comparable with that on the clean $\mathrm{TiO}_{2}(001)$ surface, while the valence band indicates that the $\mathrm{Ti} 3 d$-related defect state is completely suppressed on the oxidized surface. While it is largely unknown about the origin of surface defects on the oxidized $\mathrm{TiO}_{2}(001)$ surface, we tentatively attribute our results to the role of oxygen adatoms for a possible low-coordinated adsorption site, where ethanol may be dissociatively adsorbed. It requires however further experimental and theoretical studies to clearly address the exact origin of the binding interaction of ethanol on the oxidized $\mathrm{TiO}_{2}(001)$ surface.

\section{Conclusions}

Ethanol was used to probe the role of surface defects in the catalytic reactivity of $\mathrm{TiO}_{2}(001)$ surfaces. $\mathrm{TiO}_{2}(001)$ surfaces were prepared with various amounts of surface defects by a final annealing to $900 \mathrm{~K}, \mathrm{Ar}^{+}$-sputtering at RT and oxidation with $\mathrm{O}_{2}$ at $\mathrm{RT}$, respectively, while the nature of surface defects was characterized by measuring the Ti $2 p$ core level and the valence band photoemission spectra. Our results indicate that the saturation coverage of ethanol at RT increases when the population of the reduced surface defects (e.g., $\mathrm{Ti}^{3+}$ ) is increased. However, the maximum desorption temperature of ethanol is found to be unchanged with increased population of such reduced $\left(\mathrm{Ti}^{3+}\right)$ defects. Instead, the ethanol desorption temperature is observed to be extended to higher temperatures on the oxidized surface, where the reduced $\mathrm{Ti}^{3+}$ species are nearly depleted. We suggest that the origin of the stronger binding site for ethanol on the oxidized $\mathrm{TiO}_{2}(001)$ surface is related to a low-coordinated oxygen adatom on the surface.

Acknowledgments. This research was supported by Basic Science Research Program through the National Research Foundation of Korea (NRF) funded by the Ministry of Education, Science and Technology (2010-0010780) and by the new faculty research fund of Ajou University.

\section{References}

1. Diebold, U. Surf. Sci. Rep. 2003, 48, 53.

2. Wang, R.; Hashimoto, K.; Fujishima, A.; Chikuni, M.; Kojima, E.; Kitamura, A.; Shimohigoshi, M.; Watanabe, T. Nature 1997, $388,431$.

3. Fujishima, A.; Honda, K. Nature 1972, 238, 37.

4. Wendt, S.; Matthiesen, J.; Schaub, R.; Vestergaard, E. K.; Laegsgaard, E.; Besenbacher, F.; Hammer, B. Phys. Rev. Lett. 2006, 96, 066107.

5. Zhang, Z.; Bondarchuk, O.; Kay, B. D.; White, J. M.; Dohnalek, Z. J. Phys. Chem. B 2006, 110, 21840.

6. Li, S. C.; Zhang, Z.; Sheppard, D.; Kay, B. D.; White, J. M.; Du, Y.; Lyubinetsky, I.; Henkelman, G.; Dohnalek, Z. J. Am. Chem. Soc. 2008, 130, 9080.

7. Henderson, M. A.; Epling, W. S.; Perkins, C. L.; Peden, C. H. F.; Diebold, U. J. Phys. Chem. B 1999, 103, 5328.

8. Petrik, N. G.; Zhang, Z. R.; Du, Y. G.; Dohnalek, Z.; Lyubinetsky, I.; Kimmel, G. A. J. Phys. Chem. C 2009, 113, 12407.

9. Du, Y.; Deskins, N. A.; Zhang, Z.; Dohnalek, Z.; Dupuis, M.; Lyubinetsky, I. Phys. Rev. Lett. 2009, 102, 096102.

10. Zhang, Z.; Du, Y.; Petrik, N. G.; Kimmel, G. A.; Lyubinetsky, I.; Dohnalek, Z. J. Phys. Chem. C 2009, 113, 1908.

11. Zhang, Z. R.; Bondarchuk, E.; Kay, B. D.; White, J. M.; Dohnalek, Z. J. Phys. Chem. C 2007, 111, 3021.

12. Bondarchuk, O.; Kim, Y. K.; White, J. M.; Kim, J.; Kay, B. D.; Dohnalek, Z. J. Phys. Chem. C 2007, 111, 11059.

13. Kim, Y. K.; Kay, B. D.; White, J. M.; Dohnalek, Z. Catal. Lett. 2007, 119, 1.

14. Benz, L.; Haubrich, J.; Quiller, R. G.; Jensen, S. C.; Friend, C. M. J. Am. Chem. Soc. 2009, 131, 15026.

15. Benz, L.; Haubrich, J.; Quiller, R. G.; Friend, C. M. Surf. Sci. 2009, 603, 1010.

16. Zhang, Z.; Ge, Q.; Li, S. C.; Kay, B. D.; White, J. M.; Dohnalek, Z. Phys. Rev. Lett. 2007, 99, 126105.

17. Yim, C. M.; Pang, C. L.; Thornton, G. Phys. Rev. Lett. 2010, 104, 036806.

18. Du, Y.; Dohnalek, Z.; Lyubinetsky, I. J. Phys. Chem. C 2008, 112, 2649.

19. Wendt, S.; Sprunger, P. T.; Lira, E.; Madsen, G. K. H.; Li, Z. S.; 
Hansen, J. O.; Matthiesen, J.; Blekinge-Rasmussen, A.; Laegsgaard, E.; Hammer, B.; Besenbacher, F. Science 2008, 320, 1755.

20. Henrich, V. E.; Dresselhaus, G.; Zeiger, H. J. Phys. Rev. Lett. 1976, 36, 1335

21. Kurtz, R. L.; Stock-Bauer, R.; Madey, T. E.; Roman, E. L.; De Segovia, J. L. Surf. Sci. 1989, 218, 178.

22. Gamble, L.; Jung, L. S.; Campbell, C. T. Surf. Sci. 1996, 348, 1.

23. Kim, Y. K.; Kay, B. D.; White, J. M.; Dohnalek, Z. Surf. Sci. 2008, $602,511$.

24. Kim, Y. K.; Kay, B. D.; White, J. M.; Dohnalek, Z. J. Phys. Chem. $C \mathbf{2 0 0 7}, 111,18236$.

25. Campbell, C. T. Surf. Sci. Rep. 1997, 27, 1.

26. Farfan-Arribas, E.; Madix, R. J. J. Phys. Chem. B 2002, 106, 10680.

27. Hwang, H. N.; Kim, H. S.; Kim, B.; Hwang, C. C.; Moon, S. W.; Chung, S. M.; Jeon, C.; Park, C. Y.; Chae, K. H.; Choi, W. K. Nucl. Instrum. Methods Phys. Res. A 2007, 581, 850.

28. Mason, C. G.; Tear, S. P.; Doust, T. N.; Thornton, G. J. Phys. Condens. Matt. 1991, 3, S97.

29. Ariga, H.; Taniike, T.; Morikawa, H.; Tada, M.; Min, B. K.; Watanabe, K.; Matsumoto, Y.; Ikeda, S.; Saiki, K.; Iwasawa, Y. J.
Am. Chem. Soc. 2009, 131, 14670.

30. Perron, H.; Domain, C.; Roques, J.; Drot, R.; Simoni, E.; Catalette, H. Theor. Chem. Acc. 2007, 117, 565.

31. Ramamoorthy, M.; Vanderbilt, D.; King-Smith, R. D. Phys. Rev. B 1994, 49, 16721.

32. Kim, Y. K.; Lee, M. H.; Yeom, H. W. Phys. Rev. B 2005, 7111, 5311.

33. Palgrave, R. G.; Payne, D. J.; Egdell, R. G. J. Mater. Chem. 2009, $19,8418$.

34. Takahashi, I.; Payne, D. J.; Palgrave, R. G.; Egdell, R. G. Chem. Phys. Lett. 2008, 454, 314.

35. Nambu, A.; Graciani, J.; Rodriguez, J. A.; Wu, Q.; Fujita, E.; Fdez Sanz, J. J. Chem. Phys. 2006, 125, 094706.

36. Tait, R. H.; Kasowski, R. V. Phys. Rev. B 1979, $20,5178$.

37. Kempgens, B.; Kivimaki, A.; Itchkawitz, B. S.; Koppe, H. M.; Schmidbauer, M.; Neeb, M.; Maier, K.; Feldhaus, J.; Bradshaw, A. M. J. Electron. Spectrosc. Relat. Phenom. 1998, 93, 39.

38. Jayaweera, P. M.; Quah, E. L.; Idriss, H. J. Phys. Chem. C 2007, $111,1764$.

39. Bondarchuk, O.; Huang, X.; Kim, J.; Kay, B. D.; Wang, L. S.; White, J. M.; Dohnalek, Z. Angew. Chem. 2006, 45, 4786. 